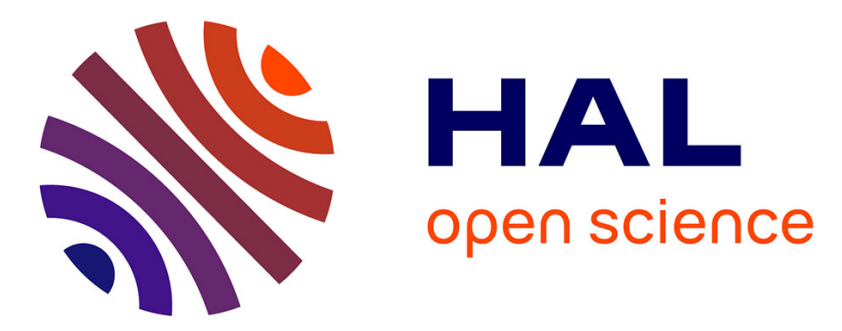

\title{
Improving rebound models in 3D rockfall simulation codes used for the design of protection embankments
}

\author{
D. Toe, Stéphane Lambert, Franck Bourrier, F. Berger
}

\section{To cite this version:}

D. Toe, Stéphane Lambert, Franck Bourrier, F. Berger. Improving rebound models in 3D rockfall simulation codes used for the design of protection embankments. Applied Mechanics and Materials, 2014, 566, pp.185-190. 10.4028/www.scientific.net/AMM.566.185 . hal-02600644

\section{HAL Id: hal-02600644 \\ https://hal.inrae.fr/hal-02600644}

Submitted on 30 Jul 2021

HAL is a multi-disciplinary open access archive for the deposit and dissemination of scientific research documents, whether they are published or not. The documents may come from teaching and research institutions in France or abroad, or from public or private research centers.
L'archive ouverte pluridisciplinaire HAL, est destinée au dépôt et à la diffusion de documents scientifiques de niveau recherche, publiés ou non, émanant des établissements d'enseignement et de recherche français ou étrangers, des laboratoires publics ou privés. 


\title{
Improving rebound models in 3D rockfall simulation codes used for the design of protection embankments
}

\author{
TOE david ${ }^{1 a}$, LAMBERT stéphane ${ }^{2 b}$, \\ BOURRIER franck ${ }^{1 \mathrm{c}}$ and BERGER frédéric ${ }^{1 \mathrm{~d}}$ \\ ${ }^{1}$ Irstea, UR EMGR, 2 rue de la Papeterie-BP 76, F-38402 Saint-Martin-d'Hères, France \\ ${ }^{2}$ Irstea, UR ETGR, 2 rue de la Papeterie-BP 76, F-38402 Saint-Martin-d'Hères, France \\ a david.toe@irstea.fr, ${ }^{\mathrm{b}}$ stephane.lambert@irstea.fr, ${ }^{\mathrm{c}}$ franck.bourrier@irstea.fr, \\ dfrederic.berger@irstea.fr
}

Keywords : Impacts, contact model, experiments.

\begin{abstract}
Rockfall propagation simulation models are widely used for assessing rockfall hazards as well as for the design of rockfall protection structures. This research work investigates the relevance of rockfall propagation models to assess rockfall hazard in the vicinity of embankments. In this article, particular focus is placed on the development of engineering oriented rebound models taking into account the shape of the block. Two different block impact modelling approaches are considered and compared. Small scale experiments involving blocks with different shapes impacting a small-scale embankment were conducted to provide data for calibrating the models. The trajectory of the blocks was tracked using a high speed camera (1000 fps) and an image processing algorithm was developed to extract the experimental trajectories. The two different approaches considered for modelling the impact of the block in the embankment vicinity were a probabilistic block impact model and a deterministic approach accounting for the block shape. In this latter case, the impact was calculated using an elasto-plastic contact model between the block and the slope surface. Both approaches succeed in simulating experimental results. Nevertheless the probabilistic model is limited by the introduction of the block shape parameter in the calculation while the deterministic approach seems to be limited in terms of computational efficiency.
\end{abstract}

\section{Introduction}

In order to protect human lives and elements at risk against rockfall hazard, defence structures such as fences or embankments are built. The positioning and the design of these protective structures are the main issues for designers, requiring conducting trajectory simulations [1]. The relevance of currently used trajectory simulation codes in the vicinity of embankments has been previously addressed by the authors [2], based on a case study. This work revealed abnormal trajectories in the vicinity of the embankment related to the spatial resolution of the terrain model and to the relevancy of the models used for the rebound of the block on the soil surface. In this context, this paper focuses on the analysis and on the modelling of the rebound of blocks against embankments.

Calculating the rebound of a block against a soil, a tree or a protection structure is a generic and key question in rockfall modelling. Different models can be used for that purpose. Probabilistic approaches that derive from analytical models considering the block as a material point, are commonly used to take into account the large variability of the slope and blocks properties. However, such approaches do not explicitly account for the shape of the blocks. More complex modelling such as those based on the Discrete Element Method (DEM) can be used to improve the classical rebound models in this sense. However, such approaches generally require calibrating a large number of input parameters and are constraining in terms of computational duration. Both probabilistic and DEM rebound models are considered in the following with the aim of finding the optimal solution, for engineering purposes. Simulation results using both approaches are compared 
to results obtained from small-scale rockfall experiments. The advantage of using small-scale experiments for rebound model assessment is that it allows conducting a large number of tests, providing statistically relevant data for model calibration and validation.

The experiments consisted in releasing successively 50 times three different blocks having different shapes on a slope, with a small-scale embankment at its end. High speed cameras images allowed determining the blocks trajectories.

\section{Materials and methods}

Experimental set up. Small scale experiments were conducted on an inclined plan followed by a horizontal plan where a small embankment was built. The slope surface and the embankment granular materials consisted of a mixture of fine well graded sand, gravel $(1 \mathrm{~mm}-4 \mathrm{~mm})$ and water, in a mass ratio of $60 / 35 / 5$. The thickness of the granular material on the slope was $1 \mathrm{~cm}$. The embankment was trapezoidal in shape, $8.3 \mathrm{~cm}$ in height and $5.5 \mathrm{~cm}$ in crest width. It was achieved by compaction of the material in successive layers in a mold and then placed on the horizontal plan by extraction of the mold. Three blocks with similar masses and of different shapes were used. The first is an idealized block (sphere) while the others are more realistic (cube and parallelepiped) (Table 1).

Table 1 Blocks characteristics

\begin{tabular}{|l|l|l|l|}
\hline Shape & Size $[\mathrm{cm}]$ & Density & Mass $[\mathrm{g}]$ \\
\hline Sphere & Diameter $: 2.5$ & 2.7 & 22.0 \\
\hline Cube & $1.9 * 1.9 * 1.9$ & 3.3 & 23.3 \\
\hline Parallelepiped & $3.5 * 1.4 * 1.4$ & 3.3 & 23.1 \\
\hline
\end{tabular}

For each block, a series of 50 release tests was conducted. The release tests consisted in dropping the block from a $30 \mathrm{~cm}$ height above the slope surface, keeping the initial orientation identical from one test to the other. The trajectories of the blocks in the embankment vicinity were filmed using a high speed camera (1000 fps). An innovative methodology for tracking the block at each step of the movie and extracting the trajectory of the block was developed. For each dropped block, the method provided the evolution of its kinematics throughout its presence in the image frame. Translational velocity and rotational velocity of the block at any point of the trajectory were calculated with the equation of ballistic flight between two impacts. The measurement of the block kinematics was globally satisfying. In most of the cases the trajectory was well defined. Nevertheless, bias was important in the case where the penetration of the block into the soil was important or when its height of rebound was small.

Probabilistic impact modelling. The probabilistic rebound model used for the simulations was taken from Bourrier and Hungr [3]. This model considers different types of coupling effects between translational velocity and rotational velocity depending on the impact angle and on the material properties. It is assumed to better reflect physical processes during the impact on the mountain side facing of the embankment where the impact angle is almost normal to the impacted surface [2]. This model is based on an analytical model of the impact of a spherical body on a horizontal surface [4].

In this model, the relation between the velocity before and after the impact is different depending on the incidence angle of the block and on the local friction angle $\varphi$ of the impacted material . Energy dissipation is modelled by means of two restitution coefficients $r_{t}$ and $r_{n}$ related with plastic dissipation processes normally and tangentially to the soil surface.

The tangential restitution coefficient is constant for any blocks incident kinematics. On the contrary, the normal coefficient $r_{n}$ is calculated from the blocks incident momentum, using an hyperbolic law. The $r_{n}$ coefficient is equal to or larger than 1 for shallow impacts where the material response 
is mostly elastic, and tends towards 0 for nearly normal impacts, where a significant amount of energy is dissipated by plastic strains. Finally, a local reduction $\alpha$ of the slope angle is introduced in the model. Introducing such a parameter is a common practice in rockfall simulations that allows accounting for both the local roughness and the block shape [5].

The model parameters $\left(M_{0.5}, r_{t}, \varphi\right)$ were calibrated for the small-scale experiments using the experimental data concerning the sphere, which shape is associated $\alpha=0^{\circ}$. Based on this calibration of $M_{0.5}, r_{t}, \varphi$, the experimental results obtained with the two other blocks allowed calibrating the values of $\alpha$ for these two block shapes.

DEM modelling. In the Discrete Element Method (DEM)-based model, the embankment is modelled as an assembly of facets and the block as an assembly of spheres. Spheres and facets are locally deformable bodies and the interaction between the block and the embankment is modelled by contact forces applied to both the block and the protective structure.

The contact law used in this model involves five calibration parameters and allows calculating the interaction forces from the block-facet relative positions and velocities. The normal component of the force to the contact surface depends on the normal penetration of the block. The force/penetration relationship accounts for plastic energy dissipation considering two stiffness coefficients: $k_{l}$ during the loading phase and $k_{u l}$ during the unloading phase [6]. The tangential force is related to the tangential displacement of the contact point following a regularized version of Coulomb's law. If slip does not occur, the tangential force is linearly related to the tangential displacement by a tangential stiffness $k_{t}$. If slipping occurs following Coulomb's law, frictional processes induce energy dissipation. The occurrence of slipping is controlled by the local friction angle $\varphi_{c}$. Finally, the contact model introduces a resisting moment at the contact point between the two bodies, allowing accounting for the formation of a soil bank inducing rolling resistance in the impact area. The resisting moment depends linearly of the block orientation by means of a rotational stiffness $k_{r}$.

Contrarily to the calibration of the probabilistic model, the choice was made to calibrate all the model parameters using the experimental data for the sphere first. Then, experimental results with the two other blocks were used for validation purpose.

For the two modelling approaches, simulations started just before the first impact in the ditch or on the mountain-side facing of the embankment. The input data for the simulations are the horizontal, vertical, rotational velocities and the coordinates of the block at this first impact.

Bases for calibration and validation. Different indicators were used to compare the results between tests and simulations. So far three measured lines have been defined (Fig.1) along the mountain-side facing of the embankment. For each, the passing frequency of the block was measured for both the test and the simulation. The calibrations of the two models were based on the comparisons of the distributions of the horizontal, vertical, rotational velocity and energy at measure line 2 for the sphere. Passing frequencies for the three measure lines were also used for that purpose. For the DEM model, the passing frequencies for the two other shapes were used to validate the model whereas, for the probabilistic model, it was used for calibrating the shape parameter $\alpha$.

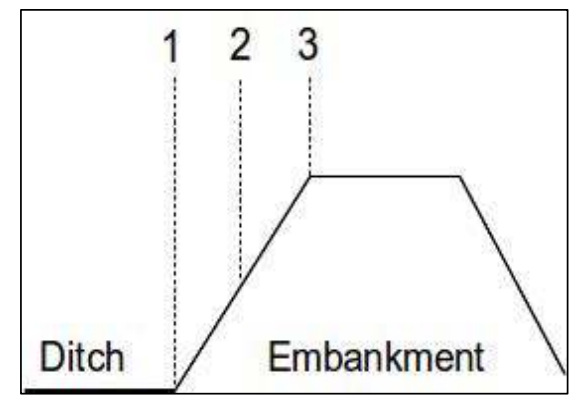

Fig.1 Localisation of the three measure lines along the mountain-side facing of the embankment 


\section{Results}

Table 2 provides for each block the successive measuring lines passing frequencies obtained for the experiments and the simulations. Experimental results show that the block shape strongly influences the block propagation with respect to the measuring lines. Depending on the block shape, line 2 is crossed by $86 \%, 32 \%$ and $6 \%$ of the blocks released. The embankment is cleared for $42 \%$ of the releases in case of the spherical block while clearing never occurs with the two other blocks. In addition to these differences in terms of run-out distance, experiments also revealed differences in terms of first impact in the embankment vicinity. For the sphere, the first impact always occurred in the ditch. With the cube, some direct impacts were located on the mountain-side facing of the embankment. And, finally, a vast majority of first impacts occurred on the embankment mountain-side facing in case of the rectangular block. In this latter case, the block trajectory was thus mainly normal to the embankment facing, suggesting a higher energy dissipation during impact.

Table 2 Measuring lines passing frequencies for the three block shape [\%]

\begin{tabular}{|c|c|c|c|c|c|c|c|c|c|}
\hline & \multicolumn{3}{|c|}{$\begin{array}{c}\text { Experimental } \\
\text { Results }\end{array}$} & \multicolumn{3}{c|}{$\begin{array}{c}\text { Probabilistic } \\
\text { Simulations }\end{array}$} & \multicolumn{3}{c|}{$\begin{array}{c}\text { DEM } \\
\text { Simulations }\end{array}$} \\
\hline & Sphere & Cube & Paral. & Sphere & Cube & Paral. & Sphere & Cube & Paral. \\
\hline Line 1 & 100 & 86 & 82 & 94 & 100 & 100 & 100 & 100 & 100 \\
\hline Line 2 & 86 & 32 & 6 & 90 & 32 & 10 & 98 & 46 & 18 \\
\hline Line 3 & 42 & 0 & 0 & 40 & 0 & 0 & 42 & 2 & 0 \\
\hline
\end{tabular}

These data resulted in the calibration of the two models, with parameters as defined in Table 3, and Table 4. As shown in Table 2, this calibration is satisfactory in terms of measure line crossing for the cube and the parallelepiped in the DEM model.

Table 3 Calibration parameters for the probabilistic model

\begin{tabular}{|c|c|c|c|c|c|c|}
\hline & \multicolumn{2}{|c|}{ Sphere } & \multicolumn{2}{c|}{ Cube } & \multicolumn{2}{c|}{ Parallepiped } \\
\hline & Ditch & Uphill face & Ditch & Uphill face & Ditch & Uphill face \\
\hline$\varphi\left[^{\circ}\right]$ & 0 & 11 & 0 & 11 & 0 & 11 \\
\hline$M_{0.5}[\mathrm{~kg} . \mathrm{m} / \mathrm{s}]$ & 0.025 & 0.04 & 0.025 & 0.04 & 0.025 & 0.04 \\
\hline$r_{t}$ & 0.85 & 0.89 & 0.85 & 0.89 & 0.85 & 0.89 \\
\hline$\alpha\left[^{\circ}\right]$ & 0 & 0 & 6 & 6 & 40 & 40 \\
\hline
\end{tabular}

Table 4 Calibration parameters for the DEM model

\begin{tabular}{|l|l|}
\hline$k_{t}[\mathrm{~N} / \mathrm{m}]$ & $2.5^{*} 10^{3}$ \\
\hline$\varphi\left[{ }^{\circ}\right]$ & 30 \\
\hline$k_{l}[\mathrm{~N} / \mathrm{m}]$ & $1 * 10^{4}$ \\
\hline$k_{r}\left[\mathrm{~N} \cdot \mathrm{m} \cdot \mathrm{rad}^{-1}\right]$ & 0,025 \\
\hline$k_{u l}[\mathrm{~N} / \mathrm{m}]$ & $6^{*} 10^{4}$ \\
\hline
\end{tabular}

In terms of kinematics, Fig.2 shows that the best fit for the sphere doesn't allow reproducing satisfactorily the distribution curves of the different parameters. DEM results at measure line 2 fit accurately the velocities, rotational velocities and the energy. However, incidence angles are smaller than experimental values. In addition, results from the probabilistic model show that the best fit allows reproducing the distributions of the rotational velocity and angle of incidence but the velocity and the energy provided are significantly higher than the experimental results. 


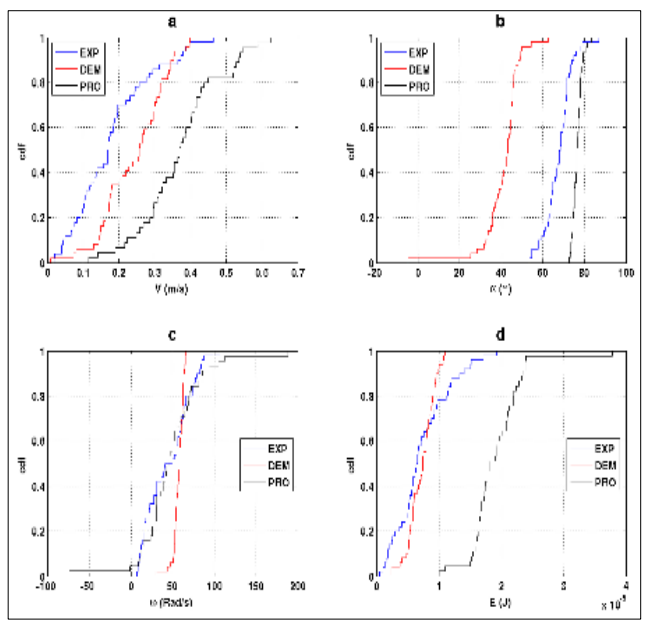

Fig.2 Cumulative distributions of the velocities (a), incidence angles (b), rotational velocities (c) and kinetic energies for experimental and simulated trajectories for the sphere at measure line 2.

The trajectories of the block extracted from simulations using the calibrated probabilistic model are in agreement with the experimental trajectories (Fig.3). Similar agreement between the simulated and experimental trajectories was observed after calibration of the DEM model for the spherical block. Simulations for the rectangular and parallelepiped block shape using the calibrated DEM model also exhibit agreement with the experimental trajectories which constitutes partial validation of the DEM approach.

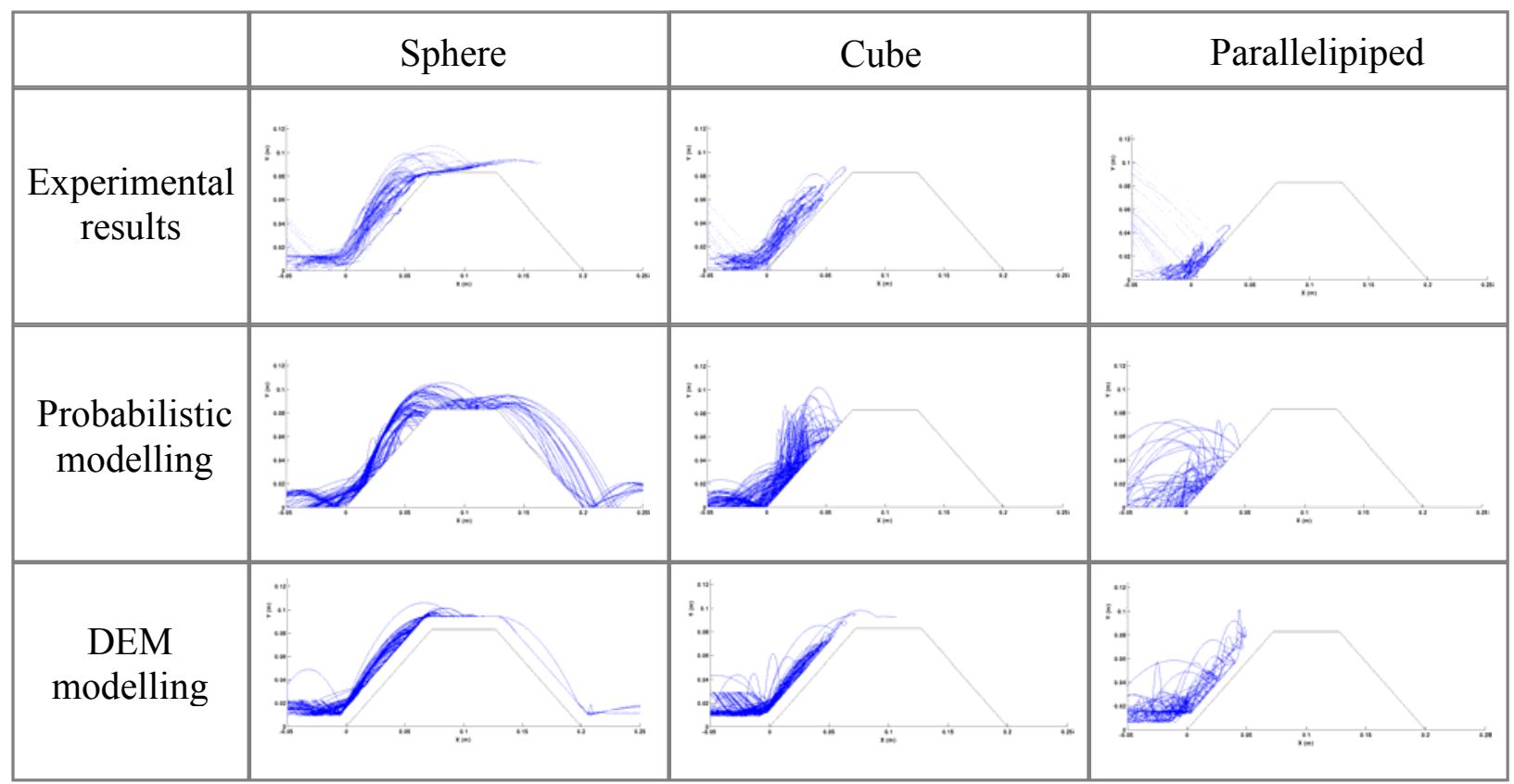

Fig.3 Experimental and simulated trajectories for the three different block shape 


\section{Conclusion}

Laboratory experiments were used for assessing the accuracy of probabilistic and DEM-based rockfall model in the vicinity of an embankment and for different block shapes. Statistically representative experimental results allowed calibrating the two models for a spherical block. Calibration of the probabilistic model was also necessary for the other block shapes due to the introduction of a block shape parameter in this model. Contrarily the DEM model was fully calibrated using the experiments for the sphere. Validation of this model was thus possible using experimental results for the cube and the parallelepiped.

The introduction of a block shape parameter in the probabilistic law is a major limitation of this approach. Contrarily, the DEM-based model allows introducing parameters depending on the material properties only. However, such an approach remains limited in terms of computational efficiency. DEM-based modelling is thus only adapted at the protective structure scale whereas probabilistic approaches remain the only feasible at the slope scale.

The two different models proposed can constitute an alternative to rebound algorithm limitations in the vicinity of an embankment exposed in [2]. Nevertheless further calibrations and validations using slope scale experiments are necessary.

\section{References}

[1] S.Lambert and F.Bourrier : Design of rockfall protection embankments: a review, Engineering geology, Vol. 154 (28), (2013), p. 77-88.

[2] S.Lambert, F.Bourrier, and D.Toe : Improving three-dimensional rockfall trajectory simulation codes for assessing the efficiency of protective embankments, International Journal of Rock Mechanics and Mining Sciences, Vol. 60, (2013), p. 26-36.

[3] F.Bourrier and O.Hungr : Rockfall dynamics: a critical review of collision and rebound models, Rockfall engineering edited by S.Lambert and F.Nicot, New York, London: John Wiley \& Sons, ISTE 1td, (2011), p. 175-210.

[4] W.Goldsmith : Impact: The theory and physical behaviour of colliding solids, Edward Arnold Ltd: London, (1960).

[5] F.Bourrier, F.Berger, P.Tardif, L.Dorren and O.Hungr : Rockfall rebound Comparison of detailed field experiments and alternative modelling approaches, Earth Surface Processes and Landforms, Vol. 37 (6), (2012), p. 656-665.

[6] R.Walton and L.Braun : Viscosity, granular-temperature, and stress calculations for shearing assemblies of inelastic, frictional disks, Journal of Rheology, Vol. 30 (5), (1985) , p. 949-980. 